\title{
Komparasi Fungsi Kernel Metode Support Vector Machine untuk Analisis Sentimen Instagram dan Twitter (Studi Kasus : Komisi Pemberantasan Korupsi)
}

\author{
Akbar Zaiem Praghakusma a,1, Novrido Charibaldi b,2 \\ ${ }^{a}$ Program Studi Informatika Universitas Pembangunan Nasional Veteran Yogyakarta, Jalan Babarsari 2, Yogyakarta 5528, Indonesia \\ ${ }^{\mathrm{b}}$ Program Studi Informatika Universitas Pembangunan Nasional Veteran Yogyakarta, Jalan Babarsari 2, Yogyakarta 5528, Indonesia \\ ${ }^{1}$ akbarzaiemp@gmail.com, ${ }^{2}$ novrido@upnyk.ac.id
}

\section{ABSTRAK}

Kinerja Komisi Pemberantasan Korupsi (KPK) yang bertugas memberantas korupsi di negeri pertiwi ini, tak jarang mendapat sorotan komentar dari berbagai kalangan masyarakat. Komentar positif, negatif maupun netral menghiasi kolom komentar di twitter maupun di instagram. Karena kolom komentar di twitter dan instagram tidak dapat mengelompokkan komentar berdasarkan jenis sentimennya (positif, negatif, atau netral) maka diperlukan sebuah sistem analisis sentimen yang dapat mengolompokkan komentar berdasarkan sentimennya. Penelitian sebelumnya yang dilakukan oleh Nooraeni, dkk (2020) tentang analisis sentimen data twitter mengenai isu RUU KPK dengan metode Support Vector Machine menggunakan kernel RBF menghasilkan akurasi sebesar $81.32 \%$, presisi sebesar $71.47 \%$, dan recall sebesar $87.64 \%$. Tujuan dari penelitian ini yaitu menerapkan dengan membandingkan kernel linier, kernel polinomial dan kernel sigmoid pada metode Support Vector Machine untuk klasifikasi analisis sentimen serta menghitung tingkat akurasi, presisi, dan recall pada tiga jenis kernel (kernel linier, kernel polinomial dan kernel sigmoid) untuk klasifikasi analisis sentimen. Penelitian ini menggunakan metode Support Vector Machine sebagai algoritma untuk menganalisis sentimen dengan membandingkan kinerja tiga jenis kernel (kernel linier, kernel polinomial dan kernel sigmoid) sebagai salah satu parameter yang dapat digunakan untuk meningkatkan akurasi metode Support Vector Machine. Hasil penelitian ini didapatkan bahwa kernel linier memiliki akurasi tertinggi sebesar $83.06 \%$, presisi sebesar $91.04 \%$, dan recall sebesar $89.70 \%$, untuk kernel polinomial memiliki akurasi sebesar $81.45 \%$, presisi sebesar $88.57 \%$, dan recall sebesar $91.17 \%$ sedangkan kernel sigmoid memiliki akurasi sebesar $79.83 \%$, presisi sebesar $91.93 \%$, dan recall sebesar $83.82 \%$.

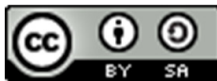

This is an open-access article under the CC-BY-SA license

\section{Pendahuluan}

Komisi Pemberantasan Korupsi (KPK) sebagai lembaga negara yang independen, tak jarang kinerjanya mendapat tanggapan beragam dari berbagai kalangan masyarakat. Indonesian Coruption Watch (ICW) menyoroti dalam laporan pemantauan kinerja KPK tahun 2020, bahwa kinerja penindakan KPK tahun 2020 menurun drastis hingga 50\% dibandingkan tahun 2019 pada jumlah penuntutan, jumlah kinerja penyidikan turun $38 \%$ dan jumlah kinerja eksekusi turun $21 \%$. Menurut survei Global Corruption Barometer tahun 2020, hanya 51\% masyarakat yang menilai bahwa kinerja KPK cukup baik pada 2020. Setiap masyarakat bebas mengutarakan komentar atas kinerja KPK melalui berbagai media, salah satunya media sosial. Penggunaan media sosial untuk 
mengutarakan opini atau pendapat terhadap suatu objek sudah menjadi kebiasaan masyarakat [1]. Media sosial untuk mengutarakan opini atau pendapat misalnya instagram dan twitter. Namun karena instagram dan twitter tidak dapat memberikan kesimpulan terhadap suatu komentar, maka perlu dikembangkan sebuah sistem cerdas untuk mengklasifikasikan komentar masyarakat di instagram dan twitter untuk mengetahui bagaimana komentar masyarakat terhadap suatu lembaga atau instansi, maka diperlukan suatu analisis sentimen. Menurut [2] analisis sentimen dapat menjadi salah satu tolak ukur untuk mengetahui atau menilai dalam hal ini citra lembaga KPK apakah mendapat citra yang baik atau buruk dari masyarakat. Ada beberapa algoritma machine learning atau metode yang dapat digunakan untuk analisis sentimen, antara lain Naüve Bayes, Support Vector Machine (SVM) dan clustering K-Means [3].

Penelitian analisis sentimen mengenai kinerja Komisi Pemberantasan Korupsi (KPK) pernah dilakukan oleh [4] dengan metode Nä̈ve Bayes, menggunakan 806 dataset dari twitter dengan 2 kelas sentimen (positif atau negatif), menunjukkan tingkat akurasi $65.51 \%$, menurut [4] hasil tersebut masih perlu dikembangkan lebih jauh lagi dengan data latih yang lebih banyak agar pengklasifikasian lebih akurat karena penggunaan bahasa dalam media sosial beragam sekali. Menurut [5] kelemahan metode Nä̈ve Bayes adalah sangat sensitif pada fitur yang terlalu banyak, sehingga akurasinya rendah. Penelitian [6] dengan metode Support Vector Machine dengan kernel Radial Bias Function (RBF) pada analisis sentimen data twitter mengenai isu RUU KPK, mengklasifikasikan sentimen menjadi 2 kelas sentimen yaitu positif atau negatif, didapatkan nilai akurasi sebesar 81,32\%. Keunggulan Support Vector Machine (SVM) berasal dari kemampuan untuk menerapkan pemisahan linear pada input data non linear berdimensi besar, dan ini diperoleh dengan menggunakan fungsi kernel yang diperlukan [7]. Kemampuan Support Vector Machine (SVM) untuk mengolah data berdimensi besar sangat cocok diterapkan pada data teks yang cenderung berdimensi besar [8]. Menurut [9] Support Vector Machine (SVM) memiliki tingkat akurasi yang tinggi dari pada metode klasifikasi Nä̈ve Bayes, Rocchio, C4.5, dan K-Nearest Neighbor pada kasus klasifiksi teks.

Model pendekatan atau biasa disebut kernel dapat membantu dalam mengatasi masalah ruang fitur (feature space), dan berpengaruh terhadap akurasi yang akan dihasilkan [10]. Menurut [11] terdapat beberapa jenis kernel dalam Support Vector Machine (SVM) selain kernel RBF yaitu kernel linier, polinomial, dan kernel sigmoid. Menurut [12] waktu pelatihan kernel linier lebih cepat dibandingkan dengan kernel lain dan cocok untuk data berdimensi besar. Pada kernel polinomial terdapat penggunaan derajat yang dapat diatur untuk meningkatkan kemungkinan data dapat dipisahkan secara linier dalam ruang berdimensi tinggi, tanpa memperlambat waktu model [13]. Pada kernel sigmoid penggunaan gamma dapat diatur untuk meningkatkan nilai akurasi akan tetapi bergantung pada jumlah fitur yang digunakan [14].

Berdasarkan uraian di atas, akan dilakukan penelitian analisis sentimen komentar masyarakat mengenai Komisi Pemberantasan Korupsi (KPK) dengan kernel linier, kernel polinomial, dan kernel sigmoid pada metode Support Vector Machine (SVM), pemilihan metode Support Vector Machine (SVM) didasarkan pada uraian penelitian sebelumnya yang menunjukkan bahwa metode Support Vector Machine (SVM) cocok dengan data berdimensi besar, serta pernyataan dari [9]. Komentar masyarakat yang didapat melalui instagram dan twitter akan diklasifikasi menjadi 3 kelas sentimen yaitu positif, negatif, atau netral. Diharapkan dapat diketahui penggunaan kernel mana yang memiliki tingkat akurasi lebih tinggi pada metode Support Vector Machine (SVM) untuk kasus pada penelitian ini, serta memberi gambaran mengenai sentimen komentar masyarakat di instagram dan twitter mengenai Komisi Pemberantasan Korupsi (KPK).

Praghakusma et.al (Komparasi Fungsi Kernel Metode Support Vector Machine) 


\section{Metode}

Algoritma yang digunakan pada penelitian ini adalah Support Vector Machine. Support Vector Machine (SVM) pertama kali diperkenalkan oleh Vapnik pada tahun 1992 sebagai konsep unggulan dalam bidang pattern recognition (memetakan suatu data ke dalam konsep class atau category yang telah didefinisikan sebelumnya), Support Vector Machine (SVM) merupakan satu metode machine learning yang bekerja atas prinsip Structural Risk Minimization (SRM) dengan tujuan menemukan hyperplane terbaik yang memisahkan dua buah class pada input space [15].

Penggunaan kernel bertujuan untuk mentransformasikan data ke ruang berdimensi tinggi, dengan menjadikan data non linier terpisah secara linier [16]. Ada beberapa pilihan fungsi kernel yang dipakai pada sebuah aplikasi untuk mengatasi masalah pada metode Support Vector Machine (SVM) [17] yaitu:

1. Linier Kernel

$$
K\left(x_{i}, x\right)=x_{i}^{T} x
$$

Dengan $x_{i}$ merupakan data latih (training), $x$ adalah data uji

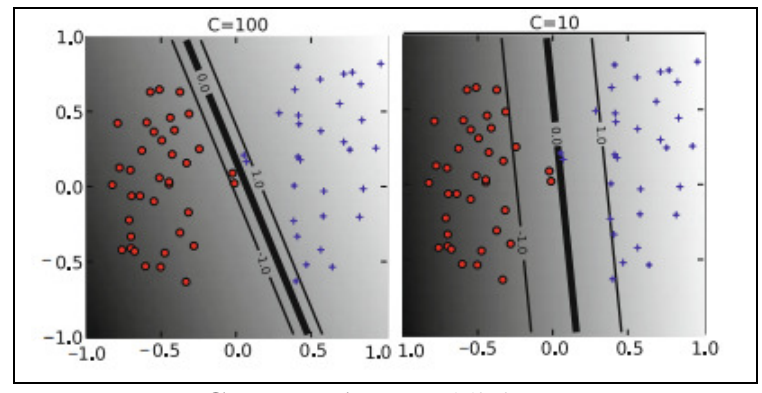

Gambar. 1. Kernel linier [18]

Pada gambar 1 terlihat bahwa penggunaan nilai $C$ yang rendah (10) akan menghasilkan nilai margin error yang rendah serta memperlebar nilai margin dan mengabaikan ignore point yang dekat dengan decision boundary, begitu sebaliknya jika nilai C yang tinggi (100) akan menghasilkan margin error besar dan mempersempit margin.

2. Polynomial Kernel

$$
K\left(x_{i}, x\right)=\left(\gamma\left(x_{i}^{T} x\right)+r\right)^{p}
$$

Dengan $x_{i}$ merupakan data latih (training), $x$ adalah data uji, $p$ adalah derajat polinomial.

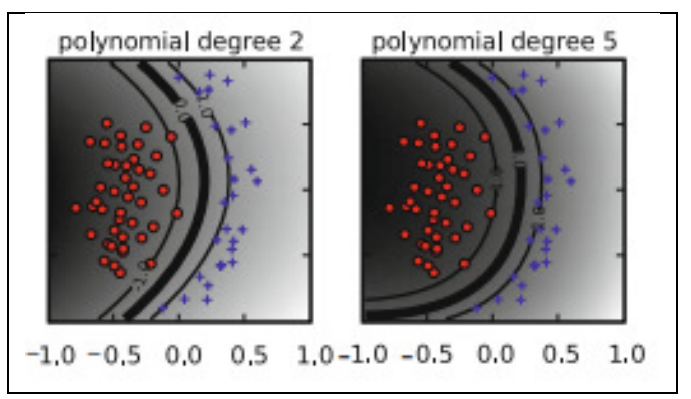

Gambar. 2. Kernel polinomial [18]

Derajat atau degree pada kernel polinomial mengontrol fleksibilitas dari hasil klasifikasi, semakin tinggi nilai degree pada kernel polinomial memungkinkan decision boundary yang lebih fleksibel [18]. Menurut [19] menggunakan derajat degree yang terlalu tinggi pada kernel polinomial dapat menyebabkan overfitting atau model yang digunakan terlalu fokus pada data 
latih, sehingga pada pengujian dengan data uji yang berbeda akan menyebabakan penurunan akurasi.

3. Sigmoid Kernel

$$
K\left(x_{i}, x\right)=\tanh \left(\gamma\left(x_{i}^{T} x\right)+r\right)
$$

Dengan $x_{i}$ merupakan data latih (training), $x$ adalah data uji, $r$ adalah koefisien

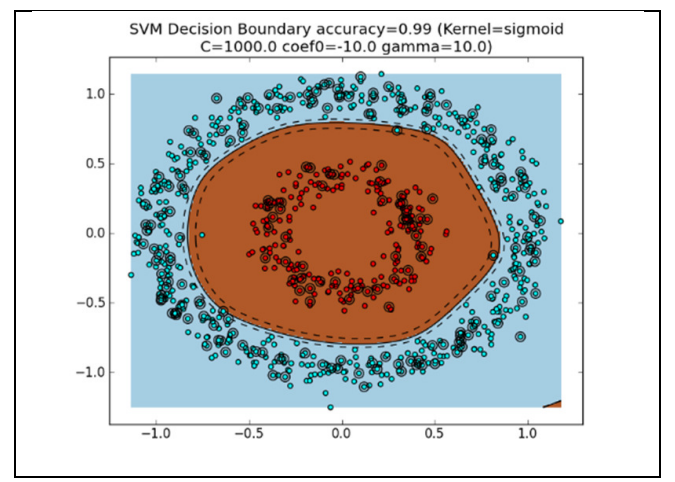

Gambar. 3. Kernel sigmoid [20]

Menurut [14] penggunaan gamma yang terlalu tinggi pada kernel sigmoid cenderung menurunkan tingkat akurasi pada suatu klasifikasi tetapi tetap bergantung pada jumlah fitur yang digunakan, semakin banyak jumah fitur maka gamma yang digunakan cenderung kecil, dan sebaliknya.

Menurut [21] untuk melakukan proses klasifikasi diperlukan suatu pemodelan Support Vector Machine (SVM) pada data latih (training) dan data uji (testing). Data latih (training) dihitung dengan menggunakan salah metode penyelesaian training data Support Vector Machine (SVM) yaitu Sequential Minimal Optimization (SMO) dengan inisialisasi $a_{i}=0$. Berikut langkah langkahnya :

1. Menghitung perhitungan kernel terlebih dahulu

2. Menghitung matriks dengan rumus sebagai berikut :

$$
D_{i j}=Y_{i} Y_{j}\left(K\left(x_{i} x_{j}\right)+\lambda^{2}\right.
$$

Keterangan:

$D_{i j}$ : Elemen matriks ke ij

$Y_{i}:$ Kelas data ke-i (label)

$Y_{j}:$ Kelas data ke-j (label)

$\lambda^{2}$ : Batas teoritis yang diturunkan

3. Menghitung nilai error

$$
E_{i}=\sum_{j=1}^{n} a_{j} D_{i j}
$$

Keterangan:

$E_{i}$ : Nilai error data ke-i

4. Menghitung delta $a_{i}$

Keterangan:

$$
\delta a_{i}=\min \left\{\max \left[\gamma\left(1-E_{i}\right),-a_{i}\right], C-a_{i}\right\}
$$

$\delta a_{i}:$ Delta a ke-i

$\gamma$ : Gamma

C : Complexity 
5. Menghitung $a_{i}$ baru

$$
a_{i} \text { baru }=a_{i}+\delta a_{i}
$$

Ulangi Langkah 3-5 hingga $a_{i}$ baru konvergen (tidak ada perubahan signifikan)

6. Menghitung nilai w. $x^{+}$dan w. $x^{-}$untuk mendapatkan nilai bias

w. $x^{+}=a_{i} Y_{i} K\left(\right.$ w. $\left.x^{+}\right)$

w. $x^{-}=a_{i} Y_{i} K\left(\mathrm{w} \cdot x^{-}\right)$

$\mathrm{b}=-\frac{1}{2}\left(\mathrm{w} \cdot x^{+}+\mathrm{w} \cdot x^{-}\right)$

Keterangan:

w. $x^{+}$: Nilai kernel data $\mathrm{x}$ dengan data $\mathrm{x}$ kelas positif yang memiliki nilai $\alpha$ tertinggi

w. $x^{-}$: Nilai kernel data $\mathrm{x}$ dengan data $\mathrm{x}$ kelas negatif yang memiliki nilai $\alpha$ tertinggi.

$\mathrm{b}$ : Nilai bias

7. Menghitung nilai keputusan

$$
f(x)=\sum_{i=1}^{m} \operatorname{sign}\left(a_{i} y_{i} K\left(x, x_{i}\right)+b\right)
$$

\section{Keterangan:}

$w:$ parameter hyperplane yang dicari (garis yang tegak lurus antara garis hyperplane dan titik support vector)

$x$ : titik data masukan Support Vector Machine

$a_{i}:$ nilai bobot setiap titik data

$K\left(x, x_{i}\right)$ : fungsi kernel

$b$ : parameter hyperplane yang dicari (nilai bias)

\section{Hasil dan Pembahasan}

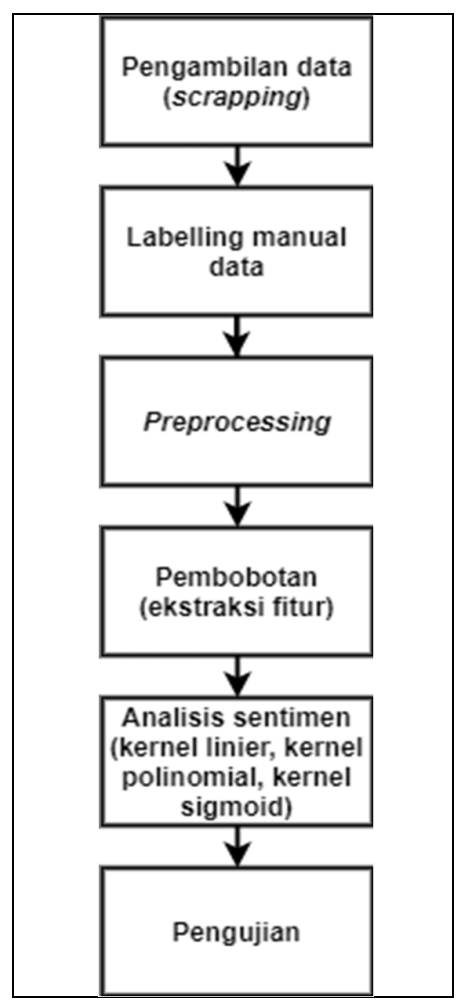

Gambar. 4. Metodologi penelitian 
Metodologi penelitian meliputi pengambilan data, labelling data secara manual, preprocessing, pembobotan, analisis sentiment, dan pengujian. Pengambilan data menggunakan metode scrapping dari tweet yang memention akun resmi KPK yaitu @KPK_RI serta pengambilan data manual di kolom komentar akun resmi KPK di instagram. Rentang waktu data latih yang digunakan dari Januari 2018 hingga November 2020, serta data uji menggunakan data Desember 2020.

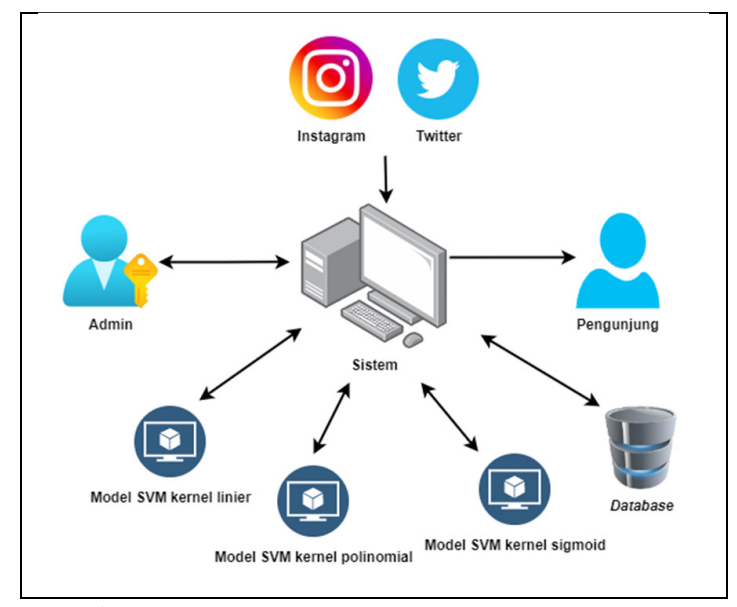

Gambar. 5. Arsitektur sistem

Perancangan arsitektur sistem bertujuan menggambarkan pemetaan rencana kebutuhan dalam suatu sistem. Terdapat 2 aktor dalam perancangan sistem ini, yaitu admin dan pengunjung. Aktor admin mempunyai akses untuk memasuki sistem dengan beberapa hak akses, antara lain mengelola kamus preprocessing, mengelola data latih, mengelola pembobotan, mengelola model Support Vector Machine (SVM), mengeloladata uji serta mendapatkan hasil analisis sentimen berserta akurasi kernel linier, kernel polinomial, dan kernel sigmoid metode Support Vector Machine (SVM). Aktor pengunjung merupakan aktor dengan akses terbatas, yaitu hanya dapat melihat hasil akurasi kernel linier dan kernel polinomial metode Support Vector Machine (SVM) serta hasil sentimen per media sosial instagram dan twitter. Teknik pengambilan data menggunakan teknik scrapping pada twitter dan pengambilan data manual pada instagram, lalu dijadikan menjadi 1 file dan disimpan di database 


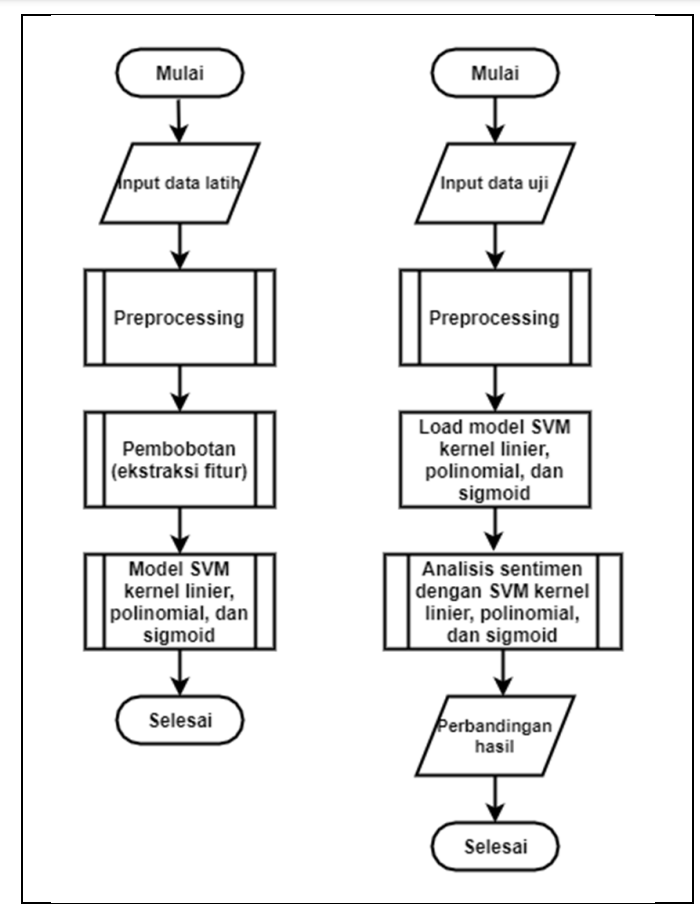

Gambar. 6. Flowchart Sistem

Gambar 5 merupakan flowchart dari sistem yang dibangun, Berikut penjelasannya :

Proses pelatihan data :

1. Data komentar dari instagram dan twitter (data latih) berjumlah 1614 (positif berjumlah 538 data, negatif berjumlah 538 data, dan netral berjumlah 538 data) data diinputkan pada sistem,

2. Kemudian komentar akan melalui tahap preprocessing. Tahap preprocessing pada sistem meliputi case folding, cleansing, tokenizing, stopword removal, dan stemming.

3. Setelah melalui tahap preprocessing, data komentar akan melalui tahap pembobotan (ekstraksi fitur) Term Frequency Inverse Document (TF-IDF).

4. Lalu sistem akan mentraining data latih dangan SVM kernel linier, kernel polinomial, dan kernel sigmoid.

5. Terakhir akan disimpan menjadi model training di model manager.

6. Selesai

Proses pengujian data :

1. Menginputkan data uji bulan Desember 2020 data dari instagram dan twitter.

2. Kemudian komentar akan melalui tahap preprocessing. Tahap preprocessing pada sistem meliputi case folding, cleansing, tokenizing, stopword removal, dan stemming.

3. Kemudian akan meload model SVM kernel linier, kernel polinomial, dan kernel sigmoid

4. Term pada data uji akan dicocokkan term data latih dan diberi bobot berdasarkan data bobot term data latih.

5. Terakhir akan dilakukan proses analisis sentimen, dan dilakukan perbandingan hasil per kenel.

6. Selesai

7. 
Tabel 1. Confusion Matrix

\begin{tabular}{cccc}
\hline & Positif & Negatif & Netral \\
\hline Positif & TP & FN & FL \\
\hline Negatif & FP & TN & FL2 \\
\hline Netral & FP2 & FN2 & TL \\
\hline Jumlah & $\mathrm{P}^{\prime}$ & $\mathrm{N}^{\prime}$ & $\mathrm{L}^{\prime}$ \\
\hline
\end{tabular}

Support Vector Machine kernel linier :

$\begin{array}{lll}\mathrm{TP}=61 & \mathrm{FN}=0 & \mathrm{FL}=7 \\ \mathrm{FP}=2 & \mathrm{TN}=22 & \mathrm{FL} 2=2 \\ \mathrm{FP} 2=4 & \mathrm{FN} 2=6 & \mathrm{TL}=20\end{array}$

Nilai Akurasi $=(T P+T N+T L) /\left(P^{\prime}+N^{\prime}+L^{\prime}\right)=83.06 \%$

Nilai Presisi $=(\mathrm{TP} /(\mathrm{TP}+\mathrm{FP}+\mathrm{FP} 2) * 100)=91.04 \%$

Nilai Recall $=(\mathrm{TP} /(\mathrm{TP}+\mathrm{FN}+\mathrm{FL}) * 100)=89.70 \%$

Support Vector Machine kernel polinomial :

$\begin{array}{lll}\mathrm{TP}=62 & \mathrm{FN}=2 & \mathrm{FL}=4 \\ \mathrm{FP}=3 & \mathrm{TN}=21 & \mathrm{FL} 2=2 \\ \mathrm{FP} 2=5 & \mathrm{FN} 2=7 & \mathrm{TL}=18\end{array}$

Nilai Akurasi $=(\mathrm{TP}+\mathrm{TN}+\mathrm{TL}) /\left(\mathrm{P}^{\prime}+\mathrm{N}^{\prime}+\mathrm{L}^{\prime}\right)=81.45 \%$

Nilai Presisi $=(T P /(T P+F P+F P 2) * 100)=88.57 \%$

Nilai Recall $=(\mathrm{TP} /(\mathrm{TP}+\mathrm{FN}+\mathrm{FL}) * 100)=91.17 \%$

Support Vector Machine kernel sigmoid :

$\begin{array}{lll}\mathrm{TP}=57 & \mathrm{FN}=2 & \mathrm{FL}=9 \\ \mathrm{FP}=2 & \mathrm{TN}=21 & \mathrm{FL} 2=3 \\ \mathrm{FP} 2=3 & \mathrm{FN} 2=6 & \mathrm{TL}=21\end{array}$

Nilai Akurasi $=(T P+T N+T L) /\left(P^{\prime}+N^{\prime}+L^{\prime}\right)=79.83 \%$

Nilai Presisi $=(T P /(T P+F P+F P 2) * 100)=91.93 \%$

Nilai Recall $=(\mathrm{TP} /(\mathrm{TP}+\mathrm{FN}+\mathrm{FL}) * 100)=83.82 \%$

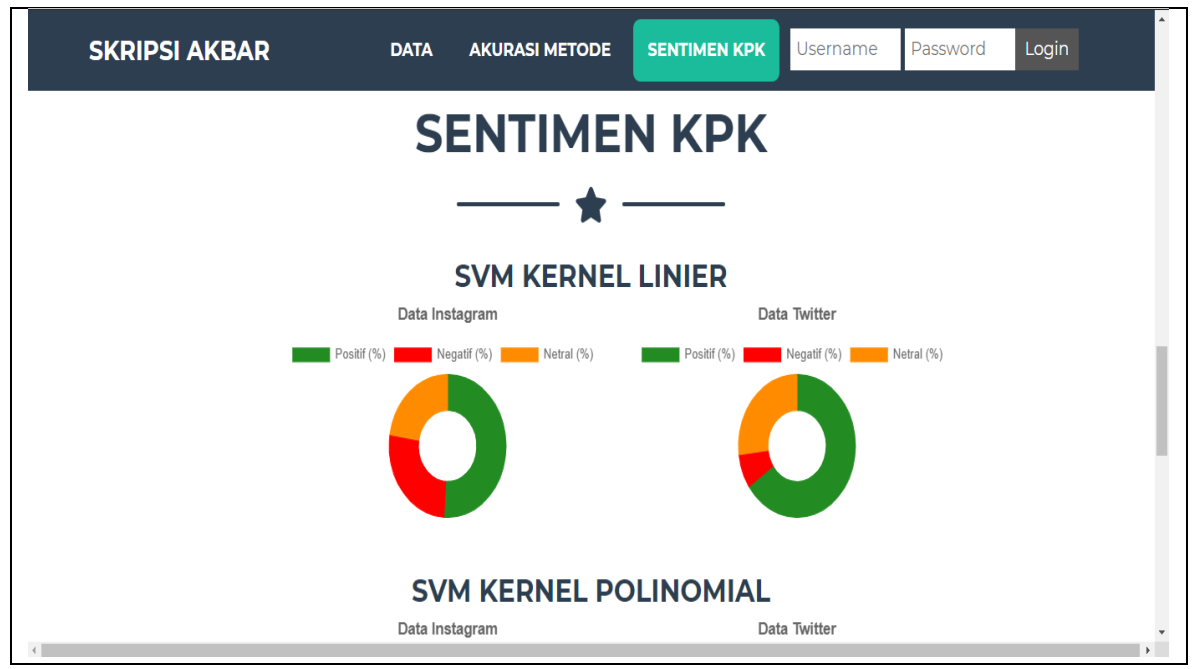

Gambar. 6. Tampilan pengunjung

Gambar 6 menampilkan tampilan User Interface (UI) untuk pengunjung dimana akan ditampilkan beberapa menu navbar, salah satunya sentimen mengenai Komisi Pemberantasan Korupsi (KPK) yang telah diuji pada komentar media sosial instagram dan twitter pada Desember 2020 


\section{Kesimpulan}

Berdasarkan hasil penelitian yang didapat, menunjukkan bahwa kernel linier memiliki nilai akurasi tertinggi dibanding kernel lainnya dangan akurasi mencapai $83.06 \%$, untuk nilai presisi kernel sigmoid memiliki nilai tertinggi dengan $91.93 \%$ dan nilai recall pada kernel polinomial memilii nilai tertinggi dibanding kernel lainnya dengan $91.17 \%$. Serta sistem analisis sentimen dapat membagi komentar data uji pada bulan Desember 2020 kedalam 3 jenis sentiment (positif, negative, ataupun netral).

\section{Daftar Pustaka}

[1]Putra, M. F., Herdiani, A., Puspandari, D., Informatika, F., \& Telkom, U. (2019). Analisis Pengaruh Normalisasi , TF-IDF , Pemilihan Feature-set Terhadap Klasifikasi Sentimen Menggunakan Maximum Entropy ( Studi Kasus : Grab dan Gojek ). 6(2), 8520-8529.

[2]Gormantara, A. (2020). Analisis Sentimen Terhadap New Normal Era di Indonesia pada Twitter Analisis Sentimen Terhadap New Normal Era di Indonesia pada Twitter Menggunakan Metode Support Vector Machine. July, 0-5.

[3]Budi, S. (2017). Text Mining Untuk Analisis Sentimen Review Film Menggunakan Algoritma K-Means. Techno.Com, 16(1), 1-8. https://doi.org/10.33633/tc.v16i1.1263

[4]H.R, R. T., Wardoyo, A. E., \& Pratama, M. R. (2018). Analisis Sentimen Pada Twitter Terhadap Kinerja Komisi Pemberantasan Korupsi (KPK) di Indonesia Dengan Metode Naive Bayes. Undergraduate Thesis, UNIVERSITAS MUHAMMADIYAH JEMBER., 7(5), 842

[5] Utami, L. D., \& Wahono, R. S. (2015). Integrasi Metode Information Gain untuk Seleksi Fitur dan AdaBoost untuk Mengurangi Bias pada Analisis Sentimen Review Restoran Menggunakan Algoritma Naive Bayes. Journal of Intelligent Systems, 1(2), 120-126.

[6] Nooraeni, R., Sariyanti, H. D., Iskandar, A. F. F., Munawwaroh, S. F., Pertiwi, S., \& Ronaldias, Y. (2020). Analisis Sentimen Data Twitter Mengenai Isu RUU KPK Dengan Metode Support Vector Machine (SVM). Paradigma - Jurnal Komputer Dan Informatika, 22(1), 55-60. https://doi.org/10.31294/p.v22i1.6869

[7] Indrayuni, E. (2018). Komparasi Algoritma Naive Bayes Dan Support Vector Machine Untuk Analisa Sentimen Review Film. Jurnal Pilar Nusa Mandiri, 14(2), 175. https://doi.org/10.33480/pilar.v14i2.918

[8] Purnawan, I. K. (2015). Support Vector Machine Pada Information Retrieval.

[9] Joachims, T. (2001). LEARNING TO CLASSIFY TEXT USING SUPPORT VECTOR MACHINES Methods, Theory, and Algorithms.

[10] Diani, R., Wisesty, U. N., \& Aditsania, A. (2017). Analisis Pengaruh Kernel Support Vector Machine (SVM) pada Klasifikasi Data Microarray untuk Deteksi Kanker. Indonesian Journal on Computing (Indo-JC), 2(1), 109. https://doi.org/10.21108/indojc.2017.2.1.169

[11] Suyanto. (2018). Machine Learning Tingkat Dasar dan Lanjut. Penerbit Informatika.

[12] Hsu, C.-W., Chang, C.-C., \& Lin, C.-J. (2016). A Practical Guide to Support Vector Classification. Theory, Culture and Society, 17(1), 1-16. https://doi.org/10.1177/02632760022050997

[13] Géron, A. (2019). Hands-on ML with Scikit-Learn, Keras \& TF by Aurelien Geron. O'Reilly Media, Inc.

[14] Al-Mejibli, I. S., Alwan, J. K., \& Abd, D. H. (2020). The effect of gamma value on support vector machine performance with different kernels. International Journal of Electrical and Computer Engineering, 10(5), 5497-5506. https://doi.org/10.11591/IJECE.V10I5.PP5497$\underline{5506}$

[15] Nugroho, A. S., Witarto, A. B., \& Handoko, D. (2003). Support Vector Machine-Teori dan 
Aplikasinya dalam Bioinformatika. Proceeding of Indonesian Scientific Meeting in Central Japan, 2003. https://doi.org/10.1109/CCDC.2011.5968300

[16] Awad, M., \& Khanna, R. (2015). Efficient learning machines: Theories, concepts, and applications for engineers and system designers. In Efficient Learning Machines: Theories, Concepts, and Applications for Engineers and System Designers (Issue May 2016). https://doi.org/10.1007/978-1-4302-5990-9

[17] Nanda, M. A., Seminar, K. B., Nandika, D., \& Maddu, A. (2018). A comparison study of kernel functions in the support vector machine and its application for termite detection. Information (Switzerland), 9(1). https://doi.org/10.3390/info9010005

[18] Ben-Hur, A., \& Weston, J. (2010). A user's guide to support vector machines. Methods in Molecular Biology (Clifton, N.J.), 609(June), 223-239. https://doi.org/10.1007/978-1-60327$\underline{241-4 \_13}$

[19] Kowalczyk, A. (2017). Support Vector Machines Succintctly, Syncfusion. Succinctly E-Book Series, 114. www.syncfusion.com.

[20] Kim, E. (2014). Everything You Wanted to Know about the Kernel Trick So, What is a Kernel Anyway? Linear SVM , Binary Classification. 1, 1-11.

[21] Jayanti, N. K. D. A., Novianti, K. D. P., \& Sumalya, I. W. (2017). Implementasi Metode Support Vector Machine Pada Sistem Pengenalan Jejaitan. Seminar Nasional Teknologi Informasi Dan Multimedia, 163-168. 